\title{
ADVANCES IN RENEWAL DECISION-MAKING UTILISING THE PROPORTIONAL HAZARDS MODEL WITH VIBRATION COVARIATES
}

\author{
Pieter-Jan Vlok \& Jasper L. Coetzee \\ Department of Mechanical and Aeronautical Engineering \\ University of Pretoria, Pretoria, 0001
}

\begin{abstract}
Increased competitiveness in the production world necessitates improved maintenance strategies to increase availabilities and drive down cost. The maintenance engineer is thus faced with the need to make more intelligent preventive renewal decisions. Two of the main techniques to achieve this is through Condition Monitoring (such as vibration monitoring and oil analysis) and Statistical Failure Analysis (typically using probabilistic techniques). The present paper discusses these techniques, their uses and weaknesses and then presents the Proportional Hazard Model as an solution to most of these weaknesses. It then goes on to compare the results of the different techniques in monetary terms, using a South African case study. This comparison shows clearly that the Proportional Hazards Model is superior to the present techniques and should be the preferred model for many actual maintenance situations.
\end{abstract}

\section{OPSOMMING}

Verhoogde vlakke van mededinging in die produksie omgewing noodsaak verbeterde instandhouding strategieë om beskikbaarheid van toerusting te verhoog en koste te minimeer. Instandhoudingsingenieurs moet gevolglik meer intellegente voorkomende hernuwings besluite neem. Twee prominente tegnieke om hierdie doelwit te bereik is Toestandsmonitering (soos vibrasie monitering of olie analise) en Statistiese Falingsanalise (gewoonlik m.b.v. probabilistiese metodes). In hierdie artikel beskou ons beide hierdie tegnieke, hulle gebruike en tekortkominge en stel dan die Proporsionele Gevaarkoers Model voor as 'n oplossing vir meeste van dié tekortkominge. Die artikel vergelyk ook die verskillende tegnieke in geldelike terme deur gebruik te maak van 'n Suid-Afrikaanse gevalle studie. Hierdie vergelyking wys duidelik uit dat die Proporsionele Gevaarkoers Model groter belofte inhou as die huidige tegnieke en dat dit die voorkeur oplossing behoort te wees in baie werklike instandhoudings situasies. 


\section{Introduction}

Often in practice, total replacement or complete overhaul to the as-good-as-new condition is the only feasible maintenance action after the failure of a component or sub-assembly. This is the only maintenance alternative considered in this paper. After such total replacement or complete overhaul, an item is said to be renewed.

Renewal of items that are bound to fail can be performed according to one of two strategies: (1) After (unexpected) component failure, in an unplanned corrective manner; or (2) Before component failure, in a planned preventive manner. The renewal action can also be totally eliminated by redesign of the component, but this approach is not always technically and economically feasible.

The different approaches to renewal mostly lead to different levels of cost. A high corrective cost, $C_{f}$, is often experienced in the case of unexpected failure renewals because it usually results in unplanned production losses and costly unscheduled maintenance actions. The cost of preventive renewal, $C_{p}$, is in most cases lower than $C_{f}$, because of the more controlled nature of this approach.

For cases where $C_{f} \gg C_{p}$ and the risk of the item to fail is increasing, preventive renewal is very often the most economic strategy and it is left to the maintenance engineer to decide when preventive renewals should take place. Three methods to assist in this decision considered in this paper are: (1) Vibration monitoring ${ }^{*}$ (assuming that the item under discussion lends itself to vibration analysis); (2) Conventional probabilistic failure analysis (such as Weibull analysis); and (3) Proportional Hazards Modelling (PHM) (originally proposed by Cox[6]) with vibration parameters as covariates. These techniques are discussed in this paper with specific reference to practices in South Africa. A data set obtained from a typical South African industry is also used to compare the different strategies.

\section{Renewal Decisions Based on Vibration Monitoring}

By analysing the vibration characteristics of a component, an enormous amount of information about the component's condition is available. This fact has been proved over and over in the past and it has encouraged researchers to develop the theory of vibration analysis up to a very high technological level. However, very little of this advanced theory and high level technology are found in the typical South African industrial organisation. Often only the most basic vibration techniques are used in condition monitoring programs.

An overview of techniques often used in preventive renewal based on vibration monitoring in South Africa is presented in this section. The term "vibration monitoring" as used here, refers to the typical vibration monitoring practices found during this study and not necessarily to the total complex field.

\subsection{Methodology}

The methodology used in the practise of vibration monitoring principally comprises of three main steps:

1. Identification of vibration analysis techniques which will warn the vibration analyst of an impending failure.

2. Setting appropriate benchmarks for the identified vibration parameters and deciding on an inspection frequency.

*Other Condition Monitoring techniques (such as oil analysis) could of course be used as well, but this paper specifically addresses the issue of vibration monitoring 
3. Monitoring the vibration levels on a regular basis and renewing the component if the specified benchmark levels are exceeded.

Steps 1 and 2 are considered to be the essence of vibration monitoring and will be considered in the paragraphs to follow. Step 3 is more of a managerial concern than a vibration monitoring task and is not discussed in this paper.

\subsection{Vibration Signal Analysis Techniques}

With vibration signal analysis software readily available, it is seldom required to have a thorough knowledge of the mathematics involved in the analysis procedures. It is however important for any engineer involved in vibration analysis to interpret analyses correctly. The following discussion thus focuses on the typical vibration signal analyses most often performed in South Africa as well as their correct physical interpretation, without emphasising mathematical calculations.

Vibration analysis techniques can be divided into two distinct categories, which are discussed below.

\subsubsection{Time Domain Analysis Techniques}

Techniques of this type are mostly favored because of its mathematical simplicity. These techniques are:

\section{- Peak signal values}

This is a very good first line analysis to distinguish between acceptable and unsatisfactory conditions, especially where essentially harmonic motion is considered. See Broch[4].

\section{- Root mean square (RMS)}

The RMS vibration level is used widely for general monitoring purposes in industry. Lui et. al.[17] published a good case study on RMS. It has the disadvantage that (1) it does not show appreciable changes in the early stages of bearing failure; and (2) cannot detect small gear defects effectively. The RMS vibration level of a signal $x(t)$ over a period $T$ is calculated by:

$$
R M S=\sqrt{\frac{\int_{0}^{T} x(t)^{2} d t}{T}}
$$

\section{- High frequency detection (HFD)}

This technique is predominantly used to detect early stages of bearing defects by trending the peak or RMS levels of the high frequency response of a machine. Kadushin[14] used HFD very successfully.

\section{- Crest factors}

The Crest Factor (CF) of a vibration signal is the ratio of the peak level to the RMS level and is a measure of impulsiveness in the signal. Norton[21] explains this concept clearly. Damaged bearings have often got CF levels exceeding 3.5.

- Probability Density Functions (PDF)of acceleration signals

Vibration accelerations recorded from a "good" bearing will have a Gaussian distributed PDF. The amount with which the measured PDF deviates from the Gaussian PDF is indicative of a bearing's condition. See Tandon and Nakra[26] for a comprehensive explanation. 


\section{- Kurtosis}

Kurtosis is also known as the fourth statistical moment of a distribution and is a measure of the distribution's spread. The Kurtosis value for a Gaussian distribution is 3 . Kurtosis values higher than 3 indicate a larger spread in a distribution which is often the first signs of a bearing defect according to Heyns[10]. It is calculated by:

$$
\text { Kurtosis }=\frac{1}{\sigma^{4} T} \int_{0}^{T} x(t)^{4} d t
$$

with $\sigma$ being the standard deviation.

\subsubsection{Frequency Domain Analysis Techniques}

Spectral analysis requires considerably more computational resources that time domain analysis primarily because the Fast Fourier Transform (FFT) of time signals has to be calculated. Frequency domain techniques often encountered are:

- Power Spectral Density analysis (PSD)

Spectral analysis is the technique used most often in vibration monitoring programs in South Africa because of its versatility. Almost any mechanical defect in rotating machinery can be identified by this type of analysis as was shown by Drouiche et. al.[8]. Spectral analysis is also the backbone of waterfall plots which is often used for decision making purposes.

- Cepstrum analysis

Cepstrum analysis is in essence the spectrum of a logarithmic spectrum and it is used to identify periodicity in the frequency spectrum. It is very useful for echo detection and for the measurement of properties of reflecting surfaces.

- High Frequency Resonance Technique (HFRT)

This is a very complex envelope detection type of technique which is often used to detect outer race defects on bearings although it is not encountered frequently. See Tandon and Nakra[26] for more information.

\subsubsection{Other}

Several other techniques which can be considered hybrids between time domain and frequency domain techniques are also at the vibration analyst's disposal. The Shock Pulse Method (SPM) is such a technique. This technique is used to identify bearing defects by tuning the transducer's resonant frequency to the expected shock-frequency caused by the damaged bearing.

Other techniques which can be of enormous value are neural networks, self organising maps, fuzzy logic, time series analysis, coherence, frequency band energy methods, trending, correlation, envelope spectra analysis, propagation path identification using causality correlation techniques, frequency response functions and the recovery of temporal waveforms of source signals. These techniques are very rarely found in South African practice.

\subsection{Typical Vibration Analysis Decision Making Techniques}

The success of vibration monitoring, as a condition monitoring maintenance strategy, is almost entirely dependent on the appropriateness of benchmarks laid upon measured vibration parameters, since the benchmarks define renewal rules. These benchmarks should be specified in such a manner that the probability of an unexpected failure is very low without wasting useful remaining life of the component.

Original equipment manufacturers (OEM's) often give guidelines regarding safe vibration 
levels for their equipment, usually by means of vibration severity charts. These guidelines are more often than not very conservative to increase product turnover. Benchmark setting based on experience is the most reliable method to achieve optimal benchmarks. This can be a very expensive exercise however, because some failures will have to take place to gain experience.

\subsection{Shortcomings of Vibration Monitoring Decision Techniques}

The theory of vibration analysis is well developed and can only be advantageous to the maintenance engineer if implemented correctly. A number of general shortcomings of vibration monitoring as practised in the South African industry were identified by Vlok et. al.[28] and are discussed below.

\subsubsection{Lack of Comparative Means between Current Vibration Condition and Past Vibration Behavior}

Very often only short term changes in vibration levels are considered when assessing component reliability, i.e. only the vibrations measured during a specific component's life time are used to predict useful remaining life. This is usually done with the aid of waterfall plots where different vibration levels are presented in a user-friendly, graphical manner such that it is easy to recognise trends in vibration behavior.

No verified or established means exist to consider long term vibration behavior in reliability estimations. Long term vibration behavior refers to vibration histories recorded from similar items that have failed under equivalent conditions in the past. Long term vibration behavior of items certainly holds extremely valuable information in terms of which current item reliability can be assessed since vibration conditions during an item's life tend to repeat itself in different components.

\subsubsection{Significance of Vibration Parameters}

Numerous vibration parameters or characteristics are usually measured and evaluated when monitoring the condition of a component as discussed above. In very few cases all of the measured parameters are significant in the failure process and often renewal decisions are made based on the level of a parameter totally insignificant in the failure process.

\subsubsection{Calculation of Optimal Renewal Instant}

Vibration monitoring is definitely not perfect as a predictive preventive maintenance strategy. A perfect predictive preventive maintenance strategy would be able to determine the exact length of an item's remaining life. No such method exists. Unexpected failures of items still do occur regardless of the fact that the vibration levels are monitored and given that unexpected failures are normally very expensive relative to preventive replacements. Thus, renewal decisions based on vibration monitoring do not bring into account the risk of an expensive unexpected failure or the possibility of loss of useful remaining life due to premature renewal.

\subsubsection{Lack of Means to Determine Vibration Monitoring Efficiency}

It is very difficult to determine the true efficiency of vibration monitoring because it is impossible to accurately predict the useful remaining life of a component which has been renewed preventively. In many cases expensive vibration monitoring programs are used to prevent unexpected failures while the difference between the cost of renewal with vibration monitoring is not much less than the cost of a run to failure strategy. 


\subsubsection{Lack of Commitment Towards Vibration Monitoring}

Vlok[27] found that there is a general lack of commitment towards vibration monitoring in industry. In many cases expensive vibration monitoring equipment is used as the flagship of the maintenance department although inspections are done very irregularly and are not recorded properly. Often the information supplied by vibration monitoring is totally disregarded when a decision has to be made and experience or intuition is relied upon. Even when the vibration information is considered, the final decision is frequently left to the discretion of the vibration technician.

It does not matter how technologically advanced vibration monitoring is, if it is not practised correctly meaningful results are impossible to obtain.

\section{Renewal Decisions based on Probabilistic Analysis of Failure Data}

Probabilistic analysis of time failure data is the most popular of four possible approaches to statistical assessment of recorded failure times arising from a renewal process. Nonprobabilistic techniques (Ascher and Feingold[2]), regression models (Crowder et. al.[7]) or neural networks (Shyur et. al.[24] and Rawicz et. al.[23]) are the other possible approaches. Probabilistic analysis is numerically attractive, straightforward to implement, easy to interpret and has had countless successes in industry.

\subsection{Methodology}

This approach strives to determine the long term minimum Life Cycle Cost (LCC) of a component by making use of a continuous statistical distribution that represents the renewal process within acceptable confidence limits. The renewal rule is to renew a particular item preventively at the instant ${ }^{\dagger}$ where the minimum LCC occurs or at failure, whichever comes first. The renewal rule balances the risk of having to spend $\mathrm{C}_{f}$ and the advantage in the cost difference between $\mathrm{C}_{f}$ and $\mathrm{C}_{p}$, without wasting useful remaining life of the item.

\subsection{Statistical Model}

The statistical distribution used most extensively to model maintenance failure data is the Weibull distribution because of its enormous flexibility. Its probability density function is given by (see Hastings[9]):

$$
f(t)=\frac{\beta}{\eta} \cdot\left(\frac{t}{\eta}\right)^{\beta-1} \cdot \exp \left(-\left(\frac{t}{\eta}\right)^{\beta}\right)
$$

The survival function corresponding to (3) is determined by:

$$
R(t)=\exp \left(-\left(\frac{t}{\eta}\right)\right)
$$

In (3) and (4) $\beta$ and $\eta$ are the shape and scale parameters of the Weibull distribution, respectively. The values of $\beta$ and $\eta$ can be calculated by maximising the likelihood function, given by Kalbfleisch and Prentice[15]:

$$
L(\beta, \eta)=\prod_{i=1}^{n} f\left(T_{i}, \beta, \eta\right)^{c_{i}} \cdot R\left(T_{i}, \beta, \eta\right)^{c_{i}-1}
$$

†Time will be the only use parameter referred to when describing an item's age in this paper although any other use parameter can be used, e.g. tonnes processed, milage, etc. 
for a data set with $n$ renewals each at time $T_{i}$ with $c_{i}=1$ in case of failure and $c_{i}=0$ for observed preventive renewals (censored observations). See Crowder et. al.[7] for a detailed discussion on censored observations. The goodness-of-fit of such fitted distribution can be evaluated with the $\chi^{2}$-test as explained by Hines and Montgomery[11].

From the fitted distribution the hazard rate of the specific item can be calculated. The hazard rate represents the instantaneous rate of failure of an item and is an indication of the item's risk to fail at a given time. It is calculated by:

$$
h(t)=\frac{\beta}{\eta} \cdot\left(\frac{t}{\eta}\right)^{\beta-1}
$$

The hazard rate is the most important function in probabilistic renewal theory because it gives guidelines regarding the choice of the most appropriate maintenance strategy. For a monotonic increasing hazard rate (increasing risk of failure with age), preventive maintenance would be a definite option although the costs involved would have the final say. The maintenance on an item with a constant or decreasing hazard rate would probably be dealt with most effectively using a corrective maintenance strategy. Condition monitoring or redesign is always a possibility however, regardless of the shape of the hazard rate.

\subsection{Calculation of the LCC per Unit Time}

With the renewal process modeled by the Weibull (or some other appropriate) distribution it is possible to calculate the LCC if renewed preventively at any time $t_{p}$, provided that the costs involved, $\mathrm{C}_{f}$ and $\mathrm{C}_{p}$, are known. The value of $t_{p}$ which results in the lowest LCC per unit time defines the renewal rule as was explained in the methodology of this approach.

The expected total LCC of an item, $\mathrm{C}_{t}$, if renewed at $\mathrm{t}_{p}$ or at failure during every cycle, is calculated by (see Coetzee[5]):

$$
C_{t}=C_{p} R\left(t_{p}\right)+C_{f}\left[1-R\left(t_{p}\right)\right]
$$

It is more convenient to express the LCC per unit time, therefore the expected cycle length has to be calculated as well:

$$
L_{e}=\left(t_{p}+T_{p}\right) R\left(T_{p}\right)+\left(t_{f}+T_{f}\right)\left[1-R\left(t_{p}\right)\right]
$$

with $\mathrm{T}_{p}$ and $\mathrm{T}_{f}$ being the time needed for preventive and failure renewals repectively. The total LCC per unit time if renewed at $t_{p}$ is thus given by $C\left(t_{p}\right)=C_{t} / L_{e}$. The minimum value of $C\left(t_{p}\right)$ defines the renewal rule and is determined by graphical inspection or differentiation.

The LCC per unit time will not always have a distinct minimum. A distinct minimum is dependent on the shape of the hazard rate of the item and the ratio between $C_{f}$ and $C_{p}$. For a clear minimum, the hazard rate should be increasing $(\beta>1)$ and $C_{f}>>C_{p}$.

\subsection{Shortcomings of Renewal Decisions based on Probabilistic Failure Analysis}

The single biggest shortcoming of probabilistic analyses as described above is the fact that it only uses recorded renewal times to model the renewal process and does not take any circumstantial influences (referred to as covariates) on renewal times into account. Circumstances in which an item operates, most often have an influence on the eventual renewal time of an item, e.g. pressure, temperature, foreign particles in lubricant, vibration levels, etc., and it makes thus sense to include these factors in the respective analyses. By doing this, the circumstantial influences are used as supporting evidence to explain the length of renewal times, thereby producing a much more accurate model. Traditional probabilistic models are however not able to do this. 


\section{Renewal Decisions with the Proportional Hazards Model and Vibration Co- variates}

Cox[6] proposed a regression model, called the Proportional Hazards Model (PHM) in 1972, originally intended for use in biomedicine to model human mortality. Ever since, countless publications have been written on the theory and application of the model. The PHM has only recently, in the mid 1980's, became popular in the field of reliability modelling and has had numerous successes (Jardine et. al.[13, 12], Love and Guo[18], Kumar[16], Ansell et. al.[1] and Bendell et. al.[3]) in modelling the mortality of machines, i.e. failure of machines.

\subsection{Methodology}

The PHM is a regression model that models the hazard rate of an item while including the effects of covariates. (Covariates can be any numerical value describing the circumstances under which an item operates. In this paper we only consider vibration parameters). Because of this attribute of the model, it is ideal to overcome the mentioned shortcomings of renewal decisions based on vibration analysis and probabilistic failure analysis in that it includes both long term failure and vibration information, as well as the current vibration condition, in the model. By doing this, the PHM produces a much more accurate representation of the actual life situation at any given time.

Renewal decisions based on the PHM with vibration covariates are also based on the minimum LCC except that the minimum is not defined in terms of time only (as was the case in subsection 3.1) but in terms of the improved proportional hazard rate, which is a function of time and covariates. Thus, an optimal risk level is calculated from recorded data of previous lives of similar items and then applied to an item currently in operation. If the working item's hazard rate, which is a function of time and the covariates measured at that time, exceeds the optimum, the item is renewed.

\subsection{Statistical Model}

The PHM consists of the product of a baseline hazard rate, dependent on time only, and a functional term, dependent on time and covariates.

$$
h(t, \bar{z})=h_{0}(t) \cdot \lambda(\bar{\gamma} \cdot \bar{z})
$$

In $(9), h_{0}(t)$ is the time-dependent baseline hazard rate, $\lambda(\bar{\gamma} \cdot \bar{z})$ is the functional term, $\bar{z}$ is a vector containing measured covariate values and $\bar{\gamma}$ is a regression vector associated with a particular data set. In practice, the exponential form of the functional term is used most often, i.e. $\lambda(\bar{\gamma} \cdot \bar{z})=\exp (\bar{\gamma} \cdot \bar{z})$. The PHM is also used predominantly in its fully Weibull parameterised form for numerical convenience, then (9) becomes:

$$
h(t, \overline{z(t)})=\frac{\beta}{\eta} \cdot\left(\frac{t}{\eta}\right)^{\beta-1} \cdot \exp (\bar{\gamma} \cdot \overline{z(t)})
$$

Note that the covariate vector $\overline{z(t)}$ in $(10)$ is presented as a function of time for the sake of generality and because vibration covariates are generally time-dependent.

The PHM as shown in (10) can be fitted to a data set by maximising the following expression for the likelihood:

$$
L(\beta, \eta, \bar{\gamma})=\prod_{i} h\left(T_{i}, \overline{z_{i}\left(T_{i}\right)}\right) \cdot \prod_{j} R\left(T_{j}, \overline{z_{j}(t)}\right)
$$

where $i$ indexes failure times and $j$ indexes both failure and suspension times. See Vlok et. al.[28] for a description of how the data should be structured for convenient numerical 
manipulation. Snyman's dynamic trajectory optimisation technique (Snyman[25]) and a modified Newton-Raphson optimisation technique (Press et. al.[22]) were found to be very efficient in maximising (11).

\subsection{Decision Making with the PHM}

A decision making technique specifically developed for the PHM by Makis and Jardine $[19,20]$ has been used successfully for vibration covariates by Vlok et. al.[28]. This model also works on the minimum LCC concept as described earlier, except that it is expressed in terms of risk.

To be able to calculate the optimal cost risk, $d$, at renewal it is necessary to predict the future covariate behavior. Markovian chains (see Hines and Montgomery[11]) are used for this prediction which results in transition probabilities of covariates from one state to the next. The expected LCC per unit time is a function of $d$ and is given by:

$$
\Phi(d)=\frac{C_{p}+\left(C_{f}-C_{p}\right) \cdot Q(d)}{W(d)}
$$

where $Q(d)$ represents the probability that a failure will occur, while $W(d)$ is the expected time until renewal, regardless of preventive action or failure. Makis and Jardine suggested algorithms with which the optimal value of $d, d^{*}$ can be calculated. The rule is to renew the item at the first instant where:

$$
\left(C_{f}-C_{p}\right) \cdot h(t, \overline{z(t)}) \geq d^{*}
$$

A warning rule is also defined as:

$$
\bar{\gamma} \cdot \overline{z(t)} \geq \delta^{*}-(\beta-1) \ln t
$$

with $\delta^{*}=\ln \left[\left(d^{*} \eta^{\beta}\right) /\left(C_{f} \beta-C_{p} \beta\right)\right]$.

\section{Case study}

Data suitable to compare the three decision making techniques as described above was found at SASOL's Twistdraai plant at Secunda. The data was recorded from September 1, 1996 to November 1, 1999 on 8 identical Warman pumps used to circulate a water and magnetite solution under equivalent conditions. A vibration monitoring maintenance strategy was historically used on the pumps as basis for renewal decisions over the 791 day data collection horison. This vibration monitoring strategy lead to several unexpected failure renewals of the pumps, which is ideal for a comparative study. In this case study the vibration monitoring strategy is evaluated and compared to conventional probabilistic failure data analysis and PHM analysis.

\subsection{Data Summary}

Data on a total of 27 histories (life times) was collected which includes 11 failure renewals, 8 suspensions and 8 temporary suspensions. (See Crowder et. al. [7] for a thorough discussion on temporary suspended observations). Horisontal vibration inspections on the bearings of the pumps were done on 98 occasions at an average of 3.6 inspections per history. Vibration measurements will not be given in this paper, see Vlok[27] and Vlok et. al.[28] for a comprehensive description of the complete data set.

The renewal times of the pumps (in days) were: Pump 1: $\left[397^{*}, 157,136^{*}, 75,26^{T S}\right]$, Pump 2: $\left[491,53^{*}, 13^{*}, 194,40^{T S}\right]$, Pump 3: [563, 15* $\left.213^{T S}\right]$, Pump 4: $\left[599^{*}, 192^{T S}\right]$, Pump 5:[184, $\left.286^{*}, 161,143,17^{T S}\right]$, Pump 6: $\left[450,341^{T S}\right]$, Pump 7: $\left[506,285^{T S}\right]$ and Pump 8: $\left[563,160^{*}\right.$, 
$68^{T S}$ ]. (Asterisks denote preventive renewals while the superscript, $T S$, refers to temporary suspensions).

Although the Twistdraai plant was willing to supply renewal data for this study, they were not able to provide real costs involved due to company policy. They did however provide scaled costs based on the average over the data collection horison of $C_{f}=\mathrm{R} 162200$ and $C_{p}=\mathrm{R} 25000$, which are proportionally correct.

\subsection{Vibration Monitoring}

Each pump has two roller element bearings between the driven pulley of the pump and the pump itself. Vibration analysts believe that by monitoring a pumps's vibration levels on the bearings, all mechanical defects, whether it comes from the pump's end or the pulley's end, will be detected. This makes good theoretical sense according to Broach[4], Kadushin[14], Norton[21] and Tandon et. al.[26] and it is also the methodology that vibration analysts concerned with the pumps at the Twistdraai plant have followed.

Vibration signals recorded from the pumps' bearings were analysed spectrally as described in subsection 2.2. Components in the vibration spectra of both bearings of special concern to the vibration technicians were:

1. $0.4 \mathrm{x} R F^{\ddagger}$ : Indicative of a particular bearing defect.

2. $1 \times R F$ : Indicative of unbalance in the pump.

3. $2 \times R F$ : Indicative of misalignment in the pump.

4. $5 \times R F$ : Indicative of cavitation in the pump.

5. HFD ${ }^{\S}$ : Indicative of early bearing defects.

6. LNF : Indicative of damage due to a lack of lubrication.

The components mentioned above were all considered to be good predictors of failure by the vibration technicians based on their experience with the pumps. Benchmarks were set for the 6 predictors and renewals were performed as soon as the benchmarks were exceeded. Waterfall plots were used as aids in the decision making process.

The real policy resulted in 11 unexpected failures and 8 preventive renewals. This resulted in a total real cost of $R 345.16$ per day. Of the total cost, $R 63.21$ per day (18.3\%) was due to preventive renewals and $R 281.95$ per day $(81.7 \%)$ due to failures.

\subsection{Probabilistic Failure Analysis}

The following statistically acceptable Weibull probability density function was obtained for the data set:

$$
f(t)=\frac{1.83}{438.69} \cdot\left(\frac{t}{438.69}\right)^{0.83} \cdot e^{-\left(\frac{t}{438.69}\right)^{1.83}}
$$

The corresponding hazard rate function is:

$$
h(t)=\frac{1.83}{438.69} \cdot\left(\frac{t}{438.69}\right)^{0.83}
$$

which is shown graphically in Figure 1.

\footnotetext{
${ }^{\ddagger} R F$ - Rotational Frequency

${ }^{\S}$ HFD - High Frequency Domain components in the frequency band $1200 \mathrm{~Hz}$ to $2400 \mathrm{~Hz}$

"LNF - Lifted Noise Floor in the frequency band $600 \mathrm{~Hz}$ to $1200 \mathrm{~Hz}$
} 


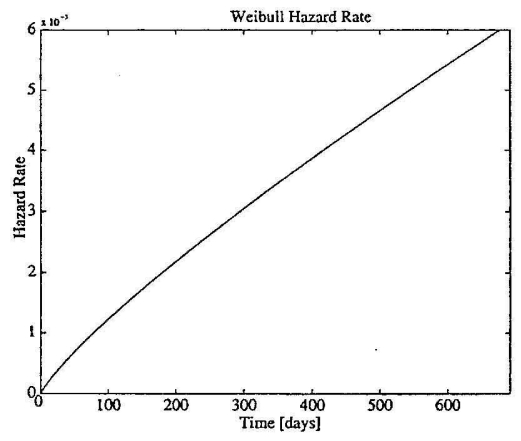

Figure 1: Weibull hazard rate

It is clear from Figure 1 that $h(t)$ is a strictly increasing function, which makes scheduled preventive renewal a definite option since $C_{f} / C_{p} \approx 6$ (fairly high). With the Weibull function known it is also possible to calculate the LCC if replaced at any time $t_{p}$ using equations (7) and (8). See Figure 2 for a graph of the LCC per unit time if replaced at $t_{p}$.

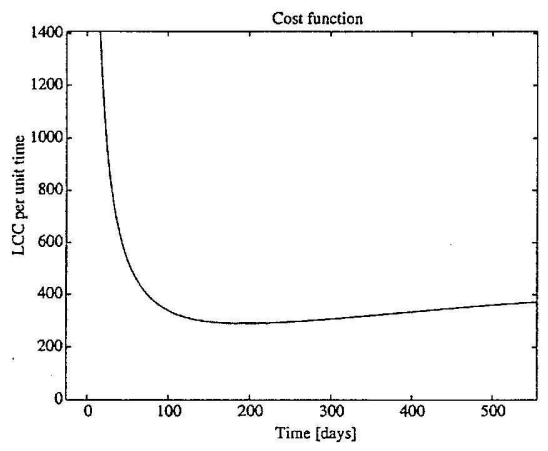

Figure 2: LCC function

A distinct optimum exist for the cost function at $t_{p}=193$ days at a cost of $\mathrm{R} 289.48$ per day, which is significantly lower than the real policy. Note that the cost function is not very sensitive close to the optimum. If the pumps were only renewed on failure the cost would be $R 413.52$ per day, which can be used as an indicator of the vibration monitoring strategy's efficiency. 


\subsection{PHM with Vibration Covariates}

For the PHM analysis, the components in the vibration spectra of importance to the vibration technicians as described above, were all used as covariates. Thus, the PHM process was started off with total of 12 covariates and then eliminated statistically (see Vlok[27]) until the PHM best describing the real situation was found as below:

$$
h\left(t, \overline{z(t)}=\frac{1.464}{1431.8} \cdot\left(\frac{t}{1431.8}\right)^{0.464} \cdot e^{0.127 \cdot R F 5_{1}+0.134 \cdot R F 5_{2}}\right.
$$

where $R F 5_{1 / 2}$ refers to $5 x R F$ of bearing 1 and $5 x R F$ of bearing 2 respectively. Equation (17) is a very surprising result in that only the two covariates associated with cavitation proved to be statistically significant in the failure process. Hence, the LCC was calculated in terms of the risk using equation (12). The results are shown in Figure 3. The minimum LCC is

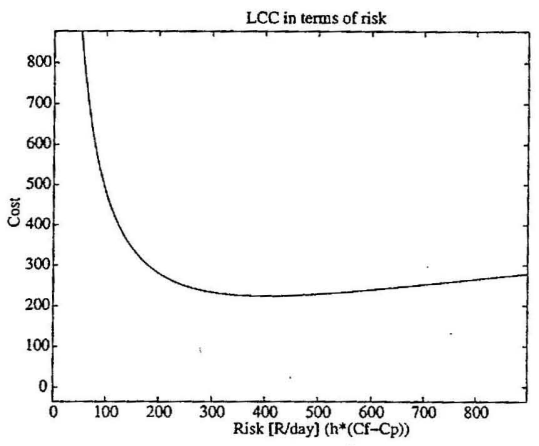

Figure 3: LCC in terms of risk

found to be $\mathrm{R} 224.04$ per day at a risk of $d^{*}=h(t, \overline{z(t)}) \cdot\left(C_{f}-C_{p}\right)=\mathrm{R} 401.41$ per day. This optimum is even lower than the value obtained with probabilistic techniques.

To test the model, the theoretical renewal policy was applied to the data set as if it was used in a real life situation. This exercise yielded a total LCC of R 214.03 per day of which $47.0 \%$ was due to preventive renewals and $53.0 \%$ due to failures. A total of $80.0 \%$ of all renewals were done preventively and only $20.0 \%$ correctively. Clearly, the calculated policy is very realistic.

\section{Conclusion}

The possible economical benefit of preventive maintenance on items which fail according to a renewal process is clearly illustrated in the theory and case study of this paper. The magnitude of this benefit is determined by the quality of renewal decisions, which is often the responsibility of the maintenance engineer.

Vibration monitoring and probabilistic failure analysis are the most frequently encountered preventive renewal decision making techniques found in South Africa for predictive and use based preventive maintenance strategies. Both these techniques have had great industrial successes despite their shortcomings. The relatively new approach of utilising the PHM with vibration covariates is an answer to many of these shortcomings. This approach enables the maintenance engineer to experience the best of both worlds, thereby making much improved renewal decisions, resulting in a very positive impact on the company's maintenance budget. 


\section{References}

[1] R O Ansell and J Ansell. Modelling the reliability of sodium sulphur cells. Reliability Engineering International, 17:127-137, 1987.

[2] H E Ascher and H Feingold. Repairable systems reliability. New York: Marcel Dekker, 1984.

[3] A Bendell, M Walley, D W Wrightman, and L M Wood. Proportional hazards modelling in reliability analysis - an application to brake discs on high speed trains. Quality and Reliability Engineering International, 2:45-52, 1986.

[4] J T Broch. Mechanical Vibrations and Shock Measurements. Bruel and Kjaer, 1980.

[5] J L Coetzee. Maintenance. Maintenance Publishers, 1997.

[6] D R Cox. Regression models and life tables (with discussion). Journal of the Royal Statistical Society, B34:187-220, 1972.

[7] M J Crowder, A C Kimber, R L Smith, and T J Sweeting. Statistical analysis of reliability data. Chapman and Hall, 1991.

[8] K Drouiche, M Sidahmed, and Y Grenier. Fault detection in gears using advanced signal processing techniques. Proceedings of the 3rd International Machinery Monitoring and Diagnosis, pages 65-71, 1991.

[9] N A J Hastings and J B Peacock. Statistical distributions. London Butterworths, 1974.

[10] P S Heyns. Mechanical Vibration: Measurement and Analysis (Course Notes). University of Pretoria, 1998.

[11] W W Hines and D C Montgomery. Probability and statistics in engineering and management science. John Wiley and Sons, 1980.

[12] A K S Jardine and M Anderson. Use of concomitant variables for reliability estimation. Maintenance Management International, 5:135-140, 1985.

[13] A K S Jardine, P M Anderson, and D S Mann. Application of the weibull proportional hazards model to aircraft and marine engine failure data. Quality and Reliability Engineering International, (5):77-82, 1987.

[14] D Kadushin. Roller element bearing fault analysis using envelope detection during an experimental case study. Proceedings of the 3rd International Machinery Monitoring and Diagnostics Conference, 1991.

[15]: J D Kalbfleisch and R L Prentice. The Statistical Analysis Of Failure Time Data. New York: Wiley, 1980.

[16] D Kumar, B Klefsjo, and U Kumar. Reliability analysis of power transmission cables of electric mine loaders using the proportional hazards model. Quality and Reliability Engineering International, (37):217-222, 1992.

[17] Y Liu, K X Chen, and S Zhang. Early detection of gearbox fault using frequency demodulation. Proceedings of the 3rd International Machinery Monitoring and Diagnosis, pages $72-76,1991$.

[18] C E Love and R Guo. Using proportional hazards modelling in plant maintenance. Quality and Reliability Engineering International, (7):7-17, 1991. 